\title{
Effects of a combined protein and antioxidant supplement on recovery of muscle function and soreness following eccentric exercise
}

Stephen J. Ives', Samuel Bloom¹, Alexs Matias', Noelle Morrow', Natalya Martins', Yookee Roh', Daniel Ebenstein', Gabriel O'Brien', Daniela Escudero', Kevin Brito', Leah Glickman', Scott Connelly² and Paul J. Arciero ${ }^{1 *}$

\begin{abstract}
Background: An acute bout of eccentric contractions (ECC) cause muscle fiber damage, inflammation, impaired muscle function (MF) and muscle soreness (MS). Individually, protein (PRO) and antioxidant (AO) supplementation may improve some aspects of recovery from ECC, though have yet to be combined. We sought to determine if combined $\mathrm{PRO}$ and $\mathrm{AO}$ supplementation (PRO + AO) improves MS and MF following damaging ECC over PRO alone.

Methods: Sixty sedentary college-aged males participated in a randomized, single-blind, parallel design study of peak isometric torque (PIMT), peak isokinetic torque (PIKT), thigh circumference (TC), and muscle soreness (MS) of knee extensor muscles measured at baseline, immediately after and 1, 2, 6, and $24 \mathrm{~h}$ after completion of 100 maximal ECC. Immediately, $6 \mathrm{~h}$, and $22 \mathrm{~h}$ post-ECC, participants consumed either: carbohydrate control $(\mathrm{CHO} ; n=14), \mathrm{PRO}(n=16)$, or PRO + AO $(n=17)$.

Results: At baseline MS, TC, MF, macro- and micro-nutrient intakes, and total work during the ECC were not different between groups $(p>0.05)$. PIMT and PIKT (both $-25 \% \Delta)$, TC $(\sim 1 \% \Delta)$ and MS $(\sim 35 \% \Delta)$ all changed with time $(p<0.05)$. We observed a group by time effect for PIKT (PRO $+\mathrm{AO}$ and PRO $>\mathrm{CHO}, p<0.05)$. At $24 \mathrm{~h}$ post ECC, there was a trend towards improved relative PIMT ( 11\%) and PIKT ( 17\%) for PRO + AO ( 17\%) and PRO ( 11\%) compared to $\mathrm{CHO}$. An interaction indicated $\mathrm{PRO}+\mathrm{AO}$ had lowest $\mathrm{MS}$ over time $(\mathrm{PRO}+\mathrm{AO}>\mathrm{PRO} \& \mathrm{CHO}, p<0.05)$.

Conclusions: Our results suggest PRO facilitates recovery of muscle function within $24 \mathrm{~h}$ following ECC, and addition of $\mathrm{AO}$ ameliorates $\mathrm{MS}$ more than $\mathrm{PRO}$ or $\mathrm{CHO}$ alone.
\end{abstract}

Keywords: Protein intake, Antioxidant supplementation, Eccentric exercise, Muscle damage, Free radicals, Muscle function

\section{Background}

Many athletic (e.g. CrossFit, wrestling, powerlifting, tennis, etc.) or occupational (e.g. military, firefighting, etc.) endeavors involve high intensity and/or eccentric muscle contractions with repeated bouts of exercise within a 24-h time frame, with as little as $0-6 \mathrm{~h}$ between efforts, or on succeeding days. An eccentric contraction occurs when a

\footnotetext{
* Correspondence: parciero@skidmore.edu

${ }^{1}$ Human Nutrition \& Metabolism Laboratory, Health and Exercise Sciences Department, Skidmore College, 815 N. Broadway, Saratoga Springs, NY 12866, USA

Full list of author information is available at the end of the article
}

muscle produces force while lengthening and is used to resist an external force. Eccentric actions, more so than concentric or isometric contractions, can result in significant structural muscle damage and soreness. Initially, eccentric exercise induces damage via mechanical stress [1], which can impair excitation contraction coupling, followed by subsequent "damage" of metabolic origin [2]. Secondarily, in response to mechanical damage, muscle fibers release pro-inflammatory cytokines (IL-1 $\beta$, TNF- $\alpha$, IL-6, and IL-8) that attract neutrophils and macrophages into muscle to ultimately repair the damaged tissue $[2,3]$. Although not a direct effect of the inflammatory response, 
muscle soreness following eccentric exercise is due to increased nociceptor and mechanoreceptor sensitivity to tissue breakdown by-products. Within muscle, leukocytes release reactive oxygen species (ROS) while cytokines may activate ROS-generating enzymes [4]. These ROS, while performing necessary breakdown of damaged tissue, may also react with healthy cellular structures, further impairing muscle function [2]. Collectively, the eccentric contraction-induced mechanical and metabolic disturbances in muscle may acutely impair muscle function and performance and increase perceived soreness $[1,2,5,6]$. Importantly, in certain athletic or occupational settings, repeated bouts of high intensity eccentric exercise with inadequate recovery may be required and thus it's paramount to develop strategies to enhance recovery in an acute time frame.

Though antioxidant supplementation is unlikely to change the inflammatory cascade [3], several studies have demonstrated the efficacy of antioxidant supplements, particularly those containing anthocyanin-rich berry extracts, in attenuating the acute decline in muscle strength due to eccentric exercise-induced muscle damage [7-9], assumedly through abatement of eccentricinduced ROS. However, the efficacy may be specific to the antioxidant [10-12]. In the current study, we utilized an anthocyanin-rich berry compound (OptiBerry ${ }^{\circ}$ ) with high Oxygen-Radical Absorbing Capacity (ORAC score $43)$ and proven antioxidant efficacy $[13,14]$. While it is debatable whether long term use of antioxidants is advised, as they may hinder the long term adaptation [15], acute supplementation following high intensity resistance exercise (e.g. eccentric contractions) appears to be effective towards restoring muscle function [7-9] and attenuating muscle soreness [16].

Post-exercise supplementation with protein or amino acids may also acutely enhance recovery from eccentric exercise [2, 17-21]. Specifically, ingestion of a whey protein supplement has been shown to enhance recovery of muscle function within $24 \mathrm{~h}$ of eccentric exercise in untrained individuals [17]. This enhanced recovery is likely due to elevated levels of free amino acids in the blood leading to increased protein synthesis and attenuated protein breakdown [22]. Additionally, protein supplementation increases satellite cell proliferation following recovery from eccentric exercise [23], a phenomenon important for the recovery of force generation [24]. However, to date, while supplementation with either protein or antioxidants have been demonstrated to be advantageous, no studies have examined the potential synergy of a combined protein (PRO) and antioxidant $(\mathrm{AO})$ supplementation $(\mathrm{PRO}+\mathrm{AO})$ on muscle recovery and soreness following eccentric exercise.

Therefore, the purpose of this study was to determine the effects of $\mathrm{PRO}+\mathrm{AO}$ on muscle soreness and muscle function following fatiguing eccentric contractions. It was hypothesized that the ingestion of recovery doses of $\mathrm{PRO}+\mathrm{AO}$ following fatiguing eccentric exercise of the knee extensor muscles would reduce perceived muscle soreness and attenuate the decline in muscle function within $24 \mathrm{~h}$ more than a carbohydrate control $(\mathrm{CHO})$ or protein (PRO) alone.

\section{Methods}

\section{Subjects and general procedures}

Sixty male college-aged students, aged 18-30, were recruited by public advertisement and word-of-mouth. Participants were relatively sedentary and did not engage in regular physical activity more than twice per week for the purpose of improving or maintaining their physical fitness. Participants had not undertaken resistance training of the quadriceps muscles and had not experienced delayed onset muscle soreness (DOMS) in their quadriceps muscles during the 3 months prior to the start of the study. Participants were free of knee, quadriceps, and other musculoskeletal, or medical problems which could interfere with their ability to perform the required exercise. Participants could not have had a previous allergic or sensitivity response to dairy proteins. All volunteers completed a Health History Questionnaire and physical activity readiness questionnaire (PAR-Q) to assess for eligibility and provided written informed consent. Approval for this study was granted by the Human Subjects Institutional Review Board of Skidmore College (IRB\#1503-451) and is in agreement with the Declaration of Helsinki as revised in 1983.

\section{Study design}

This study was conducted using a randomized, singleblind, placebo-controlled, parallel design (Fig. 1). Subjects were randomly assigned to consume $250 \mathrm{ml}$ of sugar flavored water ( $\mathrm{CHO}$ control; $31 \mathrm{~g}$ of Country Time Berry Lemonade, H.J. Heinz Company Brands LLC. Mendota Heights, MN), $250 \mathrm{ml}$ of water containing $31 \mathrm{~g}$ of whey protein hydrolysate (PRO) (Progenex

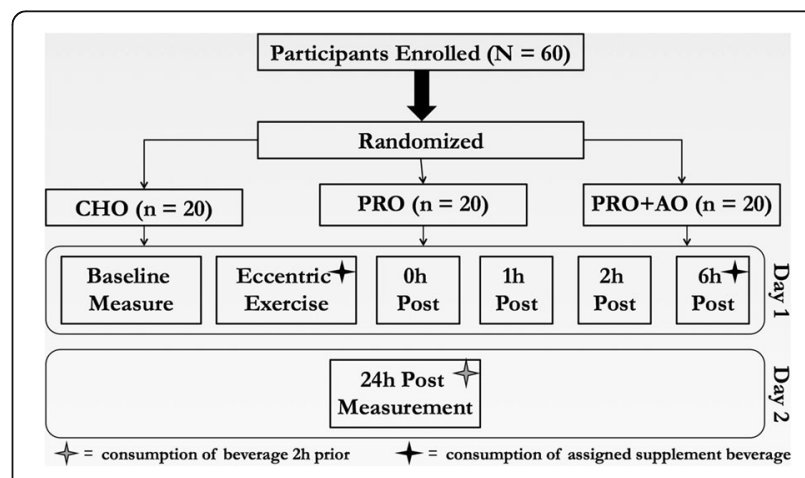

Fig. 1 Experimental Overview of the Study 
Recovery (Glanbia Thermax 690), Progenex Holdings, LLC, North Salt Lake, UT)) and non-caloric berry flavored powder (Raspberry Lemonade, Crystal Light; Kraft Heinz Company, Glenview IL), or water containing $31 \mathrm{~g}$ of whey protein hydrolysate and powdered antioxidants (PRO + AO) (Milk Specialties, MSG 9503, Eden Prairie, MN USA; 100 mg berry extract, OptiBerry ${ }^{\oplus}$, InterHealth - Lonza, Benicia, CA), all of which were isocaloric $(\sim 124 \mathrm{Kcal})$ and isovolumetric. The anthocyanin-rich berry blend (OptiBerry ${ }^{\odot}$ ) used in this study was a berry powder ( $80 \%$ solubility; standardized to 4 different anthocyanins) extract containing wild blueberry, bilberry, cranberry, elderberry, raspberry seeds, and strawberry per serving and has been demonstrated as a safe and effective antioxidant to inhibit inflammatory markers, and support vascular health $[13,14,25,26]$. Carbohydrate was chosen as a control as $\mathrm{CHO}$ supplementation has not been demonstrated to enhance or impair the recovery from eccentric exercise [27, 28]. Supplements were consumed within a 2 min period after the 100 ECC, and then immediately after the assessments at $6 \mathrm{~h}$, as well as within $2 \mathrm{~h}$ prior to the $24 \mathrm{~h}$ assessment. Additionally, subjects reported their perceived like/dislike of the supplements via a Hedonic 9-point scale, where the anchor point towards the far left was "Strongest Imaginable Dislike" and to the right was "Strongest Imaginable Like." Assessment of taste was included as this is often a determining factor in adherence to nutritional supplementation use.

To minimize the impact of diet, all subjects were given an example low antioxidant diet to follow for the day preceding and the day of the study (See Additional file 1: Table S1). To assess dietary intakes between groups and determine compliance a 2 day dietary record was obtained over the study period and analyzed. To characterize the participants, height and weight were measured using standard techniques and body fat percentage, body fat mass, and fat-free mass were measured using the air displacement plethysmography technique (BodPod, Cosmed, Chicago, IL). Volunteers were instructed to refrain from taking over-the-counter medication, "cold \& flu" treatments, analgesics, aspirin or other anti-inflammatory preparations for at least 7 days prior to the study, and to abstain from caffeine and alcohol for 24 and $48 \mathrm{~h}$ prior to the study, respectively. Subjects reported to the lab after an overnight fast $(\sim 12$ a.m). As a means of standardization, prior to the 100 maximal ECC and the $24 \mathrm{~h}$ assessment, subjects were given a standard breakfast bar (Nature Valley 'Crunchy Oats 'n Honey', General Mills, Inc., Minneapolis, MN) to consume.

\section{Assessment of muscle function}

Assessments of peak isokinetic torque (PIKT) and peak isometric torque (PIMT) of the knee extensor muscles of the right leg, as well as perceived muscle soreness (MS) and thigh circumference measures were obtained prior to the performance of 100 maximal ECCs of the knee extensors of the right leg, immediately after ECC, and at 1, 2, 6, and $24 \mathrm{~h}$ post-ECC (Fig. 1). All measurements were obtained from the right leg on all study participants and all non-involved body parts were immobilized throughout all Cybex testing to remove superfluous movement. Both static and dynamic muscle actions were chosen as previous research has suggested the temporal response between muscle actions may differ [6], and dynamic muscle actions more closely mimic those often used in sport or occupational performance. PIKT and PIMT were assessed using the HUMAC NORM (Cybex) ergometer which has been demonstrated to be a reliable ergometer $[29,30]$. After $5 \mathrm{~min}$ of easy cycling $(\sim 1 \mathrm{kp})$ on an ergometer (Monark 828E; Vansbro, Sweden), participants subsequently performed a warm up set of 3 repetitions on the Cybex. PIMT was determined by using the best of 3 maximal isometric contractions of the knee extensors with the knee flexed at an angle of $90^{\circ}$. For isokinetic measurements, after a warm up set of 5 repetitions, subjects performed 1 set of 5 repetitions of isokinetic contractions of the knee extensors, through an individually determined range of motion $\left(\sim 90^{\circ}\right)$ at an angular velocity of $40^{\circ s-1}$. The highest value obtained during the 5 repetitions was recorded and ranged from 120 to $150 \mathrm{ft}$.lb. of peak torque. The total warm up lasted approximately 7-10 min. As eccentric contractions may alter sarcomere length, and the optimal length for tension development [1], optimal joint angle, a surrogate for length, was recorded, amongst other variables obtained from the dynamometer. Body position, approximate axis of rotation of the knee joint and dynamometer lever arm length were recorded and thus consistent for all trials for each volunteer. Verbal encouragement was provided during all contractions to ensure maximal effort and was consistent between sessions and participants. The minimum eccentric torque needed to lower the arm and initiate the dynamometer was $\sim 5 \mathrm{ft} \mathrm{lb.}$

\section{Muscle soreness}

Muscle soreness was evaluated using a visual analog scale (VAS) [31]. The VAS consisted of a $100 \mathrm{~mm}$ long horizontal line with anchor points on either side stating "no soreness" on the far left and "worst soreness possible" on the far right. Subjects were seated with right leg in passive $90^{\circ}$ of flexion at the beginning of the soreness evaluation and instructed to extend the knee of the right leg (parallel to the floor) to full extension. Subjects then placed a mark at the point on the VAS corresponding to their perception of the soreness of the right quadriceps muscle. This was done both unweighted and 
weighted with a 5-kg mass suspended from the ankle. Muscle soreness was quantified by using the measured distance $(\mathrm{mm})$ from the left end of the continuum to the mark made by the subject. Additionally, a Gulick tape measure was used to quantify the circumference of the right thigh at the midpoint between the greater trochanter of the femur and the knee joint to assess for localized swelling. This location was marked (with a permanent marker) as means of standardization and to maintain consistency during follow-up measurements.

\section{Eccentric exercise}

On the first day of testing, following baseline measures, subjects performed 100 maximal eccentric contractions (ECCs) of the knee extensors of the right leg on a HUMAC NORM isokinetic dynamometer (Boston, USA) at an angular velocity of $40^{\circ \mathrm{s}-1}$ through an $80^{\circ}$ range of motion (Fig. 1). To the initiate each ECC, subjects performed a brief concentric contraction against the dynamometer lever arm of approximately $5 \mathrm{ft} \mathrm{lb}$, and then with continual maximal effort resisted the force of the ergometer lengthening their knee extensors. The knee extensors were relaxed at the end of each ECC, and during the recovery phase the relaxed leg was returned to the starting position by the dynamometer. The dynamometer provides real-time feedback to monitor effort during the ECC. This protocol was chosen as it has been used previously, with success, to determine the impact of dietary interventions on muscle soreness and function [17]. Verbal encouragement was provided to ensure maximal effort in a consistent manner during all contractions for all participants. Those who didn't exhibit a $\geq 10 \%$ decline in peak isometric torque at the $0 \mathrm{~h}$ measure, immediately after the ECC, were excluded from the study.

\section{Data analysis}

A one way analysis of variance (ANOVA) was used to compare baseline parameters between the three supplement groups. To determine the effects of the supplements (control vs PRO vs $\mathrm{PRO}+\mathrm{AO}$ ) on the dependent measures (PIMT, VAS, and thigh circumference) over time, two-way mixed model ANOVA (group (3) x time (6)) were used. Where a significant main effect was observed, a post hoc analysis was conducted to identify differences between means using Tukey's HSD test. To account for potential minor variations in baseline muscle function (ie. PIMT, PIKT), muscle function was normalized to initial and represented as the change from baseline. Alpha was set, a priori, at 0.05 for all comparisons. All data was presented as mean \pm standard error of the mean (SE).

\section{Results}

\section{Participant characteristics}

No significant differences were observed for age, height, weight, percent body fat, fat free mass, and initial thigh circumference between groups (Table 1). Due to failure to meet the $\geq 10 \%$ decline in peak isometric torque following ECC, study completion rates were 70\% (14/20), 80\% (16/ $20)$, and $85 \%(17 / 20)$ for $\mathrm{CHO}, \mathrm{PRO}$, and $\mathrm{PRO}+\mathrm{AO}$ groups, respectively. There were no significant differences between the groups at the start of ECC testing.

\section{Dietary record and taste analysis}

There was no significant difference $(p>0.05)$ in macronutrient dietary consumption (kilocalories, protein, fat, carbohydrate) for all three treatment groups for the day prior and day of the initial testing, as assessed using 2 day food logs (Table 2). There were no differences in vitamin $\mathrm{A}$, vitamin $\mathrm{C}$, potassium, sodium, calcium, and iron intake between groups (Table 2). A significant difference was observed in cholesterol intake for the day prior to initial testing where $\mathrm{CHO}$ group had greater intake than PRO and PRO + AO ( $p=0.03)$ (Table 2).

Regarding taste of the supplements, $\mathrm{CHO}$ had a significantly greater average score for taste on the Hedonic scale than the PRO supplement $(p<0.001)$, however, there was no difference in taste score between $\mathrm{PRO}+\mathrm{AO}$ and $\mathrm{CHO}$ $(p=0.079)$ or $\mathrm{PRO}+\mathrm{AO}$ and PRO $(p=0.111)$.

\section{Muscle function}

At baseline, there was no significant differences in both isometric $(p=0.529)$ and isokinetic $(p=0.575)$ muscle function between all three treatment groups (Table 3).

Table 1 Subject characteristics by group

\begin{tabular}{|c|c|c|c|c|}
\hline Variable & $\mathrm{CHO}(n=14)$ & $\mathrm{PRO}(n=16)$ & $\mathrm{PRO}+\mathrm{AO}(n=17)$ & $p$-value \\
\hline Age (yrs) & $21.3 \pm 1.0$ & $20.9 \pm 0.5$ & $20.6 \pm 0.3$ & 0.76 \\
\hline Height (cm) & $175.4 \pm 1.9$ & $177.2 \pm 1.8$ & $180.5 \pm 1.2$ & 0.09 \\
\hline Weight (kg) & $71.8 \pm 4.1$ & $72.5 \pm 3.6$ & $72.2 \pm 2.6$ & 0.99 \\
\hline Body Fat (\%) & $17.0 \pm 2.6$ & $14.0 \pm 1.7$ & $14.6 \pm 1.2$ & 0.56 \\
\hline Fat Free Mass (kg) & $74.9 \pm 9.8$ & $62.8 \pm 2.6$ & $61.2 \pm 1.8$ & 0.18 \\
\hline Thigh Circumference (cm) & $53.5 \pm 2.1$ & $53.1 \pm 1.5$ & $54.3 \pm 1.2$ & 0.85 \\
\hline
\end{tabular}

Data are mean \pm SE 
Table 2 Dietary analysis from 2 day food log, not including study supplementation

\begin{tabular}{|c|c|c|c|c|c|}
\hline Variable & & $\mathrm{CHO}(n=14)$ & $\mathrm{PRO}(n=16)$ & $\mathrm{PRO}+\mathrm{AO}(n=17)$ & $p$-value \\
\hline \multirow[t]{2}{*}{ Calories (kcal) } & Day 1 & $1917 \pm 138$ & $2069 \pm 229$ & $1861 \pm 182$ & 0.42 \\
\hline & Day 2 & $1655 \pm 137$ & $1725 \pm 210$ & $1626 \pm 151$ & 0.81 \\
\hline \multirow[t]{2}{*}{ Carbohydrates (g) } & Day 1 & $198 \pm 11(41 \%)$ & $253 \pm 40$ (49\%) & $217 \pm 26(47 \%)$ & 0.74 \\
\hline & Day 2 & $190 \pm 27(46 \%)$ & $209 \pm 40(48 \%)$ & $179 \pm 21(44 \%)$ & 0.59 \\
\hline \multirow[t]{2}{*}{ Fat (g) } & Day 1 & $80 \pm 10(37 \%)$ & $74 \pm 8(32 \%)$ & $68 \pm 9(33 \%)$ & 0.35 \\
\hline & Day 2 & $67 \pm 6(36 \%)$ & $55 \pm 10(29 \%)$ & $55 \pm 9(30 \%)$ & 0.71 \\
\hline \multirow[t]{2}{*}{ Protein (g) } & Day 1 & $93 \pm 7$ (19\%) & $98 \pm 9(19 \%)$ & $88 \pm 6(19 \%)$ & 0.23 \\
\hline & Day 2 & $98 \pm 11(24 \%)$ & $94 \pm 14(22 \%)$ & $81 \pm 8(20 \%)$ & 0.54 \\
\hline \multirow[t]{2}{*}{ Protein (g/kg) } & Day 1 & $1.35 \pm 0.23$ & $1.40 \pm 0.24$ & $1.13 \pm 0.12$ & 0.29 \\
\hline & Day 2 & $1.40 \pm 0.21$ & $1.14 \pm 0.20$ & $1.11 \pm 0.13$ & 0.57 \\
\hline \multirow[t]{2}{*}{ Vitamin A (mg) } & Day 1 & $152 \pm 70$ & $64 \pm 16$ & $65 \pm 20$ & 0.20 \\
\hline & Day 2 & $48 \pm 18$ & $44 \pm 13$ & $104 \pm 35$ & 0.23 \\
\hline \multirow[t]{2}{*}{ Vitamin C (mg) } & Day 1 & $171 \pm 59$ & $181 \pm 62$ & $79 \pm 27$ & 0.26 \\
\hline & Day 2 & $72 \pm 19$ & $34 \pm 16$ & $74 \pm 19$ & 0.29 \\
\hline \multirow[t]{2}{*}{ Sodium (mg) } & Day 1 & $2458 \pm 129$ & $2667 \pm 353$ & $3068 \pm 622$ & 0.73 \\
\hline & Day 2 & $2439 \pm 414$ & $1781 \pm 330$ & $1995 \pm 436$ & 0.36 \\
\hline \multirow[t]{2}{*}{ Potassium (mg) } & Day 1 & $1113 \pm 286$ & $1103 \pm 144$ & $1229 \pm 320$ & 0.79 \\
\hline & Day 2 & $1549 \pm 300$ & $1303 \pm 238$ & $1322 \pm 260$ & 0.68 \\
\hline \multirow[t]{2}{*}{ Calcium (mg) } & Day 1 & $84 \pm 28$ & $67 \pm 18$ & $51 \pm 7$ & 0.43 \\
\hline & Day 2 & $54 \pm 9$ & $46 \pm 10$ & $44 \pm 11$ & 0.84 \\
\hline \multirow[t]{2}{*}{ Iron (mg) } & Day 1 & $70 \pm 23$ & $74 \pm 18$ & $59 \pm 10$ & 0.78 \\
\hline & Day 2 & $55 \pm 7$ & $41 \pm 6$ & $53 \pm 8$ & 0.30 \\
\hline \multirow[t]{2}{*}{ Cholesterol (mg) } & Day 1 & $582 \pm 134$ & $291 \pm 61$ & $250 \pm 70$ & 0.03 \\
\hline & Day 2 & $344 \pm 86$ & $414 \pm 226$ & $280 \pm 94$ & 0.79 \\
\hline
\end{tabular}

Data are mean $\pm \mathrm{SE}$

Table 3 Baseline measures of isometric and isokinetic muscle function

\begin{tabular}{|c|c|c|c|c|}
\hline Variable & $\mathrm{CHO}(n=14)$ & $\mathrm{PRO}(n=16)$ & $\mathrm{PRO}+\mathrm{AO}(n=17)$ & $\overline{p \text {-value }}$ \\
\hline \multicolumn{5}{|l|}{ Isometric } \\
\hline Peak Torque (ft.lb) & $152 \pm 12.3$ & $159 \pm 8.8$ & $167 \pm 7.2$ & 0.59 \\
\hline Average Torque (ft.lb) & $134 \pm 11.2$ & $139 \pm 7.7$ & $147 \pm 6.8$ & 0.56 \\
\hline Slope (ft.lb./s) & $138 \pm 15.4$ & $122 \pm 19.1$ & $134 \pm 21.3$ & 0.84 \\
\hline Time to $1 / 2$ Peak (sec) & $0.16 \pm 0.02$ & $0.24 \pm 0.03$ & $0.19 \pm 0.04$ & 0.22 \\
\hline Time to Peak (sec) & $1.94 \pm 0.29$ & $2.38 \pm 0.30$ & $2.56 \pm 2.46$ & 0.30 \\
\hline \multicolumn{5}{|l|}{ Isokinetic } \\
\hline Peak Torque (ft.lb) & $138 \pm 9.9$ & $126 \pm 7.9$ & $135 \pm 7.1$ & 0.58 \\
\hline Work per Rep (J) & $133 \pm 10.6$ & $124 \pm 8.3$ & $127 \pm 8.9$ & 0.23 \\
\hline Average Power (W) & $78 \pm 6.6$ & $70 \pm 5.2$ & $74 \pm 4.9$ & 0.46 \\
\hline Joint Angle at Peak (deg) & $66 \pm 2.5$ & $68 \pm 2.7$ & $69 \pm 2.2$ & 0.69 \\
\hline Time to Peak (sec) & $0.85 \pm 0.09$ & $0.84 \pm 0.07$ & $0.73 \pm 0.08$ & 0.48 \\
\hline Time Peak Held (sec) & $0.04 \pm 0.01$ & $0.09 \pm 0.05$ & $0.07 \pm 0.01$ & 0.60 \\
\hline Force Decay Time (sec) & $1.43 \pm 0.05$ & $1.48 \pm 0.06$ & $1.42 \pm 0.08$ & 0.79 \\
\hline Reciprocal Delay (sec) & $0.65 \pm 0.21$ & $0.34 \pm 0.08$ & $0.36 \pm 0.10$ & 0.24 \\
\hline Delay Time (sec) & $-0.07 \pm 0.08$ & $-0.04 \pm 0.00$ & $-0.05 \pm 0.01$ & 0.89 \\
\hline
\end{tabular}


During the ECC, total eccentric work (CHO: $13,639 \pm 1036 \mathrm{ft} \cdot \mathrm{lbs}$, PRO: $12,458 \pm 622 \mathrm{ft} \cdot \mathrm{lbs}, \mathrm{PRO}+\mathrm{AO}$ : $13,518 \pm 431 \mathrm{ft} \cdot \mathrm{lbs})$ and peak eccentric torque (CHO: $196 \pm 13 \mathrm{ft} \cdot \mathrm{lbs}$, PRO: $178 \pm 8 \mathrm{ft} \cdot \mathrm{lbs}$, PRO + AO: $206 \pm 8$ $\mathrm{ft}$.lbs) during the eccentric exercise were not significantly different between groups.

Peak isometric torque, expectedly, was significantly reduced $(p<0.001)$ following the ECC (Fig. 2a). However, there was no main effect of group $(p=0.324)$ nor an interaction of group over time $(p=0.882)$ for PIMT. When expressed as percent of baseline (Fig. 2b) there was again an effect of time ( 25\% decrease, $p<0.001)$, but no significant group effect $(p=0.127)$ or group over time interaction effect $(p=0.529)$ for PIMT.

Peak isokinetic torque, also exhibited a significant drop in torque over time (Fig. 3a) $(p<0.000)$, with a significant interaction effect for PIKT for group over time $(p=0.047$, Fig. 3a), where the PRO and PRO + AO groups had greater forces than the $\mathrm{CHO}$ group. When post hoc tests were conducted, a significant difference was observed between $\mathrm{CHO}$ group and $\mathrm{PRO}$ and

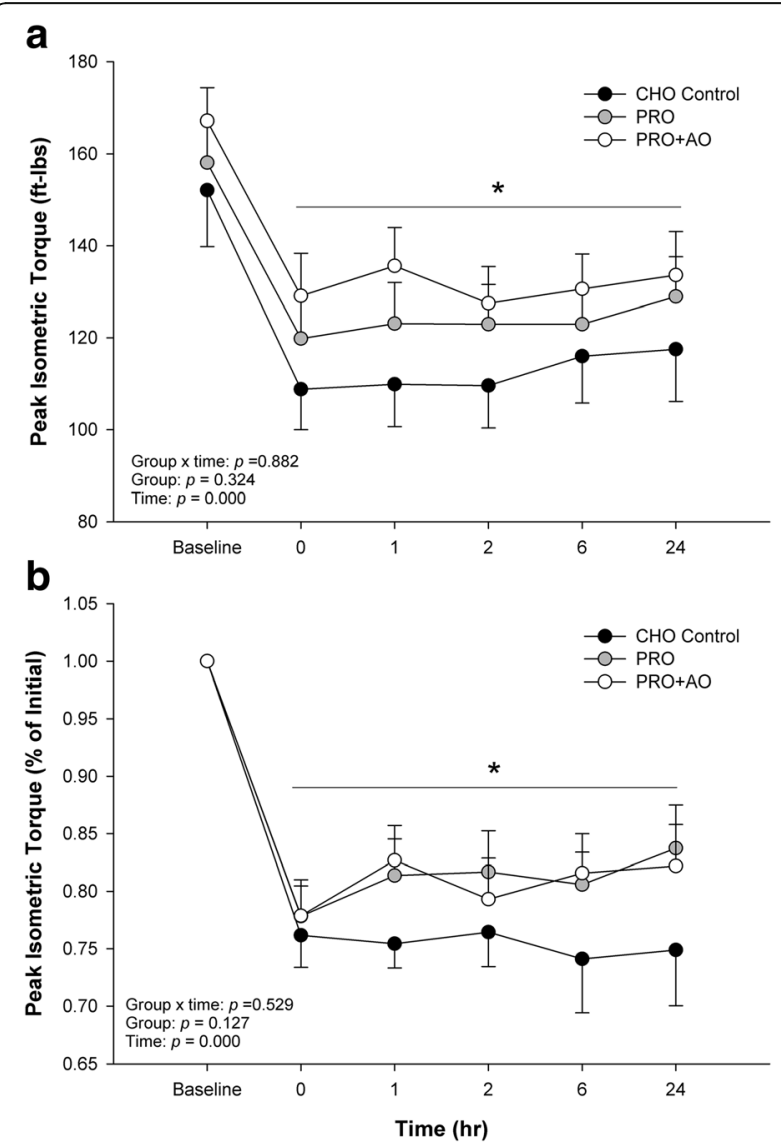

Fig. 2 The Impact of Supplementation $(\mathrm{CHO}, \mathrm{PRO}, \mathrm{PRO}+\mathrm{AO})$ on Absolute Isometric Muscle Function (Panel a) and Change in Isometric Muscle Function from Baseline (Panel b). ${ }^{*} p<0.05$ individual time points vs. baseline. Data are mean \pm SE

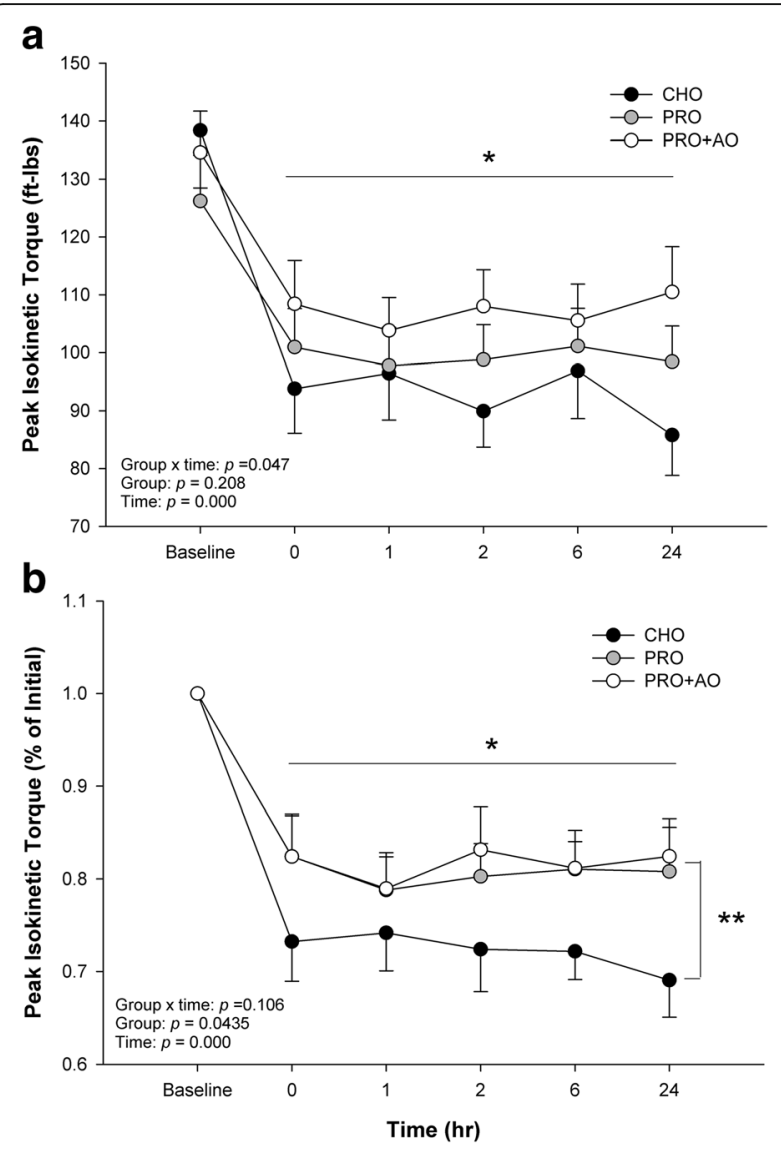

Fig. 3 The Impact of Supplementation $(\mathrm{CHO}, \mathrm{PRO}, \mathrm{PRO}+\mathrm{AO})$ on Absolute Isokinetic Muscle Function (Panel a) and Change in Isokinetic Muscle Function from Baseline (Panel b). ${ }^{*} p<0.05$ individual time points vs. baseline; ${ }^{* *} p<0.05 \mathrm{CHO}$ vs. PRO and PRO + AO. Data are mean \pm SE

PRO $+\mathrm{AO}$ groups at the $24 \mathrm{~h}$ time point $(p=0.026$, Fig. $3 a)$, though, the main effect for group was not significant $(p=0.208)$. When expressed as percent of baseline (Fig. $3 \mathrm{~b})$, the effect of time was again significant $(\sim 25 \%$ decline, $p<0.001$ ), and there was a significant main effect for group $(p=0.0435)$ but no interaction effect of group over time $(p=0.106)$ for PIKT (Fig. 3b). Post hoc testing of group effects revealed that both PRO (11\% difference) and PRO + AO (17\% difference) groups had significantly higher, on average, peak isokinetic torques than the $\mathrm{CHO}$ control group.

\section{Muscle soreness and thigh circumference}

All groups experienced a significant increase in unweighted and weighted muscle soreness following the ECC (Fig. 4a-b, $p<0.001$ ). For unweighted VAS, there was a significant interaction of group and time $(p=0.033)$, where the $\mathrm{PRO}+\mathrm{AO}$ group had the lowest soreness over time. Post hoc testing showed PRO + AO was lower than PRO at $0,1,2$, and $6 \mathrm{~h}$ post ECC 

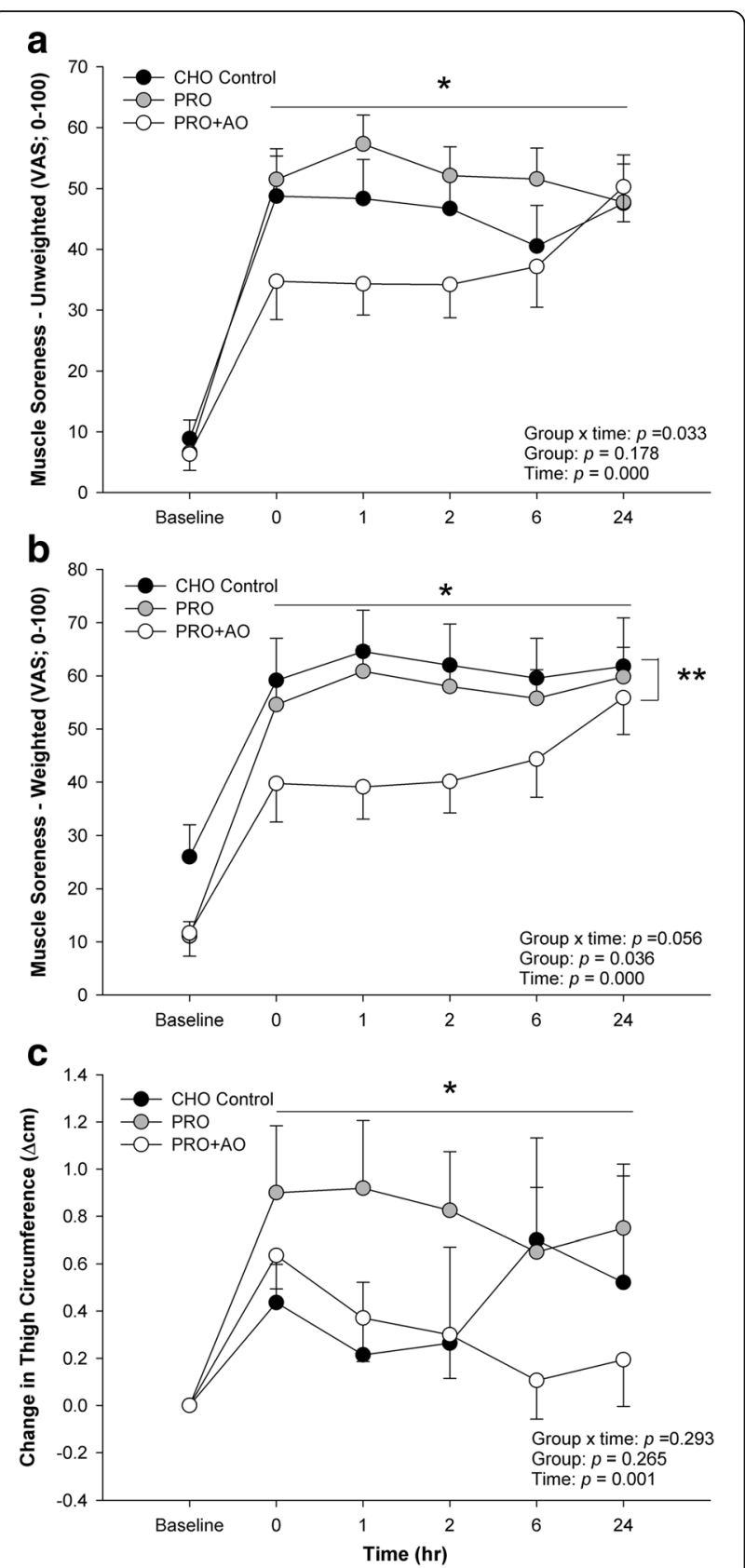

Fig. 4 The Impact of Supplementation on Changes in Muscle Soreness and Swelling. a Unweighted Visual analog scale for soreness, b Weighted VAS for soreness, and c Change in Thigh Circumference $(\mathrm{CHO} n=14, \mathrm{PRO} n=16, \mathrm{PRO}+\mathrm{AO} n=17) .{ }^{*} p<0.05$ individual time points vs. baseline; ${ }^{* *} p=0.027, \mathrm{CHO}$ vs. $\mathrm{PRO}+\mathrm{AO}$. Data are mean $\pm \mathrm{SE}$

$(p=0.02,0.001,0.009$, and 0.04), and tended to be lower than $\mathrm{CHO}$ alone at 0,1 , and $2(p=0.07,0.05$, and 0.07$)$. However, there was no significant main effect of group $(p=0.178)$. For the weighted VAS, there was a trend for an interaction effect of group over time $(p=0.056)$ and a significant group effect $(p=0.036$, Fig. $4 \mathrm{~b})$, with $\mathrm{PRO}+\mathrm{AO}$ reporting the lowest soreness compared to
PRO and CHO. Finally, there was a significant increase in thigh circumference over time ( $p=0.001$, Fig. $4 c)$, but no significant group $(p=0.265)$ or group by time interaction effects $(p=0.293)$.

\section{Discussion}

The purpose of this study was to determine if a combined protein and antioxidant supplement $(\mathrm{PRO}+\mathrm{AO})$ was more effective than either protein (PRO) or carbohydrate control $(\mathrm{CHO})$ alone in restoring muscle soreness and muscle function following fatiguing eccentric contractions (ECC) during the acute $24 \mathrm{~h}$ phase. The primary findings of this study demonstrate that during the acute $24 \mathrm{~h}$ period following fatiguing ECC exercise: 1) muscle function is significantly reduced and muscle soreness and thigh circumference are increased; 2) both groups that supplemented with PRO tended to have better isometric muscle function, and significantly greater isokinetic muscle function over $\mathrm{CHO}$ control; and 3) combined protein and antioxidant supplementation $(\mathrm{PRO}+\mathrm{AO})$ tended to have better absolute isokinetic torque and significantly less perceived soreness over time when compared to protein alone (PRO) or a carbohydrate $(\mathrm{CHO})$ control. Collectively, the current findings support protein supplementation to enhance recovery of muscle function and the addition of antioxidants to act synergistically to reduce perceived muscle soreness, in the hours immediately following ECC exercise. Thus, the combination of protein and antioxidants may be an important consideration in developing and implementing strategies to aid in muscle recovery during the acute $(0-24 \mathrm{~h})$ time period following a bout of exhaustive eccentric exercise.

\section{Muscle function}

Indeed many athletic events that involve high intensity and/or eccentric contractions often require short turnaround times to subsequent events $(0-6 \mathrm{~h})$, which does not allow for adequate muscle recovery. For instance, the CrossFit games, wrestling tournaments, powerlifting competitions, tennis tournaments, etc., all require multiple high intensity bouts within a given day, and perhaps on successive days. Thus, developing supplementation strategies to improve recovery and reduce muscle soreness, might improve performance in such settings. In terms of aiding recovery of muscle function from resistance exercise or eccentric exercise, supplementation with protein or amino acids post-exercise has been demonstrated to enhance recovery $[17,19,20,22]$. Regarding isometric muscle function, previous work by Buckley and colleagues [17] found that consumption of whey protein hydrolysate resulted in a quicker recovery in peak isometric torque following ECC, with complete recovery at $6 \mathrm{~h}$ post exercise. Similarly, the current study found at $24 \mathrm{~h}$ 
post ECC, peak isometric torque was higher, on average, though not statistically, in both $\mathrm{PRO}+\mathrm{AO}$ and PRO groups compared to the $\mathrm{CHO}$ group, by 16 and $11 \mathrm{ft} \mathrm{lb}$., respectively (Fig. 2a), or approximately a $38 \%$ difference in peak isometric torque (\% of initial) between protein supplemented groups and $\mathrm{CHO}$ control (Fig. 2b). However, unlike the Buckley et al. study [17], and others [18], which found supplementation with protein completely restored and even surpassed baseline peak isometric torque [17], we did not find resolution of force within the same observed timeframe (Fig. 2), though the PRO supplemented groups seemed to have a positive slope towards recovery, where the $\mathrm{CHO}$ did not. Although total work between groups was not reported in these earlier studies, even concentric muscle force contractions are suppressed following high intensity work [32]. In any case and even though our measurements did not extend to $48 \mathrm{~h}$ post ECC, the pattern of our reported muscle function data (Figs. 2 and 3) seems to suggest we observed a similar pattern as others in this regard [23, 28, 33].

As muscle function, broadly defined, is impaired following ECC, the magnitude and temporal pattern may depend upon contraction type; specifically, static versus dynamic, and concentric versus eccentric $[5,6]$. Thus, it's paramount to examine both static and dynamic muscle function, with the latter likely being more important for performance. Examination of dynamic peak isokinetic torque from the current study, we found a group by time interaction when expressed as absolute torque, whereby $\mathrm{CHO}$ control experiences the most dramatic decline in torque, followed by PRO, whereas $\mathrm{PRO}+\mathrm{AO}$ appears least affected (Fig. 3a). Similarly, when expressed as percent of initial peak torque, there was a group effect with $\mathrm{PRO}$ and $\mathrm{PRO}+\mathrm{AO}$ groups having a higher on average peak isokinetic torque (Fig. $3 \mathrm{~b})$, or approximately a $17 \%$ difference between PRO supplemented groups and $\mathrm{CHO}$ control group (Fig. 3b). Thus, in agreement with previous studies [18], the present study suggests protein supplementation following ECC does, in fact, improve recovery of dynamic muscle function. However, it is unlikely that dynamic muscle function returns to baseline levels within an acute time frame $(<48 \mathrm{~h})$, independent of supplementation [23, 28, 33].

Furthermore, previous research has demonstrated that supplementation with antioxidants derived from fruit improves recovery of muscle function following fatiguing eccentric exercise [7-9], though not all agree [34]. These studies contained either whole fruit or pasteurized fruit juices containing a combination of anthocyanins with phenolic compounds, flavonoids, ellagitannins, and/or ellagic acid. In the current study, using an antioxidant derived from anthocyanin extract from mixed berries, we found no synergistic effect of supplementing with both protein and antioxidants, or the antioxidant offered no obvious additional benefit beyond that of protein alone (Figs. 2 and 3). In agreement, previous studies have also found no effect of antioxidant supplementation (using either vitamin $\mathrm{C}$ or fruit, berry and vegetable concentrate) on muscle recovery [10, 11, 34]. In contrast, previous studies using either a berry or fruit derived antioxidant supplement demonstrate an interaction between groups with no clear direction of improved muscle function [9] or show enhanced recovery of muscle function with a pre-loading period prior to ECC [8]. Collectively, future work is needed to determine if optimal dosing strategy, types of antioxidants, may influence the impact of antioxidant supplementation on muscle function following fatiguing eccentric exercise.

\section{Muscle soreness}

Decline in muscle function, athletic performance, and intensification of muscle soreness are all correlated to the damaging effects of eccentric exercise on muscle. Studies investigating the effect of protein or amino acids on muscle soreness following ECC have yielded both positive $[19,20,22]$ and null $[17,18,23,28]$ effects. In the present study, using both unweighted and weighted conditions to assess perceived muscle soreness, we show only protein and antioxidant supplementation $(\mathrm{PRO}+\mathrm{AO})$ favorably impacts perceived muscle soreness (via visual analog scales) for both weighted and unweighted conditions (Fig. 4a and b). While there was a significant time effect for increased thigh circumference indicative of swelling and localized inflammatory responses, no group or group by time effects were found.

Our finding of significantly lower perceived muscle soreness over time in combined protein and antioxidant (PRO + AO) supplementation compared to PRO and $\mathrm{CHO}$ groups is intriguing (Fig. 4a). The current finding supports prior work suggesting antioxidant supplementation may reduce muscle soreness following ECC $[7,11$, 34], although the positive effect of antioxidants on muscle soreness is not unanimous [8-10]. Although the precise mechanism(s) for reduced muscle soreness is unknown, it may be related to either the high leucine or essential amino acid content within whey protein [35], antioxidants potential to reduce muscle soreness following ECC exercise [36], or may be related to the many bioactives present within various forms of whey protein. In any case, this finding may prove beneficial in scenarios where subsequent bouts with inadequate recovery are necessitated (e.g. tournament play, multiple sport events, military or occupational scenarios).

\section{Experimental considerations}

While the findings of this study demonstrate improved muscle function, and attenuated muscle soreness with 
combined protein and antioxidant supplementation, further evaluation of this recovery strategy is necessary. Specifically, the type, dose, and dosing strategy (pre-loading, frequency of dosing, etc.) likely needs optimization. Additionally, while muscle function is paramount, analysis of blood markers of muscle damage and oxidative stress, could provide insight into the underlying mechanisms of protein and antioxidant supplementation in the recovery of muscle soreness and function following eccentric exercise. On the contrary, previous studies which have measured blood markers of oxidative stress or muscle damage (e.g. creatine kinase) that were discordant with function $[3,8,9,11,34]$, in that muscle function would be improved but not oxidative markers, or vice versa, calling into question the value of such measurements. Additionally, observing the effect of the supplement across a larger time period (up to $92 \mathrm{~h}$ or resolution of soreness/function), as well as in trained, competing athletes in which this is primarily intended to benefit, are suggested.

\section{Conclusions}

The current study adds to the growing body of evidence supporting the benefits of ingesting protein following high intensity eccentric exercise and extends it by demonstrating that a combined $\mathrm{PRO}+\mathrm{AO}$ supplement may further mitigate the eccentric-induced decrements in muscle function and reduce muscle soreness in the acute time frame $(0-24 \mathrm{~h})$ following the eccentric bout. Collectively, a combined protein antioxidant supplement is likely beneficial in the recovery from eccentric exercise, and may be relevant for novice exercisers or in athletic or occupational scenarios where a repeated bout is required before full recovery is allowed.

\section{Additional file}

Additional file 1: Table S1. Meal Plan for the day before, day of testing, and following morning before $24 \mathrm{~h}$ testing period. (DOCX $12 \mathrm{~kb}$ )

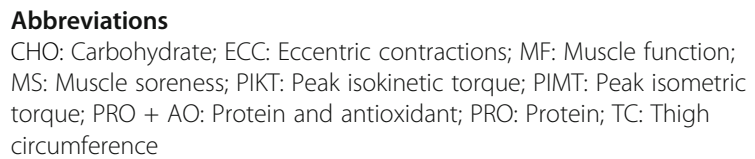
MS: Muscle soreness; PIKT: Peak isokinetic torque; PIMT: Peak isometric torque; PRO + AO: Protein and antioxidant; PRO: Protein; TC: Thigh circumference

\section{Acknowledgements}

We are grateful to Chelsea Norton for all of her help with subject recruitment, testing and data collection. We are thankful to all of the study participants who volunteered their time for this study.

\section{Funding}

This study was funded by a grant from Scott Connelly Foundation to PJA and SJ.

\section{Availability of data and materials}

The data that support the findings of this study are available from Scott Connelly Foundation but restrictions apply to the availability of these data, which were used under license for the current study, and so are not publicly available. Data are however available from the authors upon reasonable request and with permission of Connelly Research Foundation.

\begin{abstract}
Authors' contributions
PJA, SC, and SJl conceived and designed the experiments; SJI, PJA, SB, AM, $N M, N M, Y R, D E, G O, D E, K B$, LG performed the experiments; SB, AM, NM, NM, $Y R, D E, G O, D E, K B, L G, S J I$ and PJA analyzed the data; SJ and PJA wrote the manuscript. SJI, PJA, and SC commented on the manuscript; All authors read and approved the final manuscript.
\end{abstract}

\section{Ethics approval and consent to participate}

This study was approved by the Institutional Review Board of Skidmore College (IRB\#1503-451) and all subjects provided written and signed consent to participate.

\section{Consent for publication \\ Not applicable.}

\section{Competing interests}

The authors declare they have no competing interests.

\section{Publisher's Note}

Springer Nature remains neutral with regard to jurisdictional claims in published maps and institutional affiliations.

\section{Author details}

${ }^{1}$ Human Nutrition \& Metabolism Laboratory, Health and Exercise Sciences Department, Skidmore College, 815 N. Broadway, Saratoga Springs, NY 12866, USA. ${ }^{2}$ Scott Connelly Foundation, Corona Del Mar, CA, USA.

Received: 1 April 2017 Accepted: 27 June 2017

Published online: 03 July 2017

\section{References}

1. Proske U, Morgan DL. Muscle damage from eccentric exercise: mechanism, mechanical signs, adaptation and clinical applications. J Physiol. 2001;537(Pt 2):333-45.

2. Pereira Panza VS, Diefenthaeler F, da Silva EL. Benefits of dietary phytochemical supplementation on eccentric exercise-induced muscle damage: is including antioxidants enough? Nutrition. 2015;31(9):1072-82.

3. Petersen EW, Ostrowski K, Ibfelt T, Richelle M, Offord E, Halkjaer-Kristensen J, Pedersen BK. Effect of vitamin supplementation on cytokine response and on muscle damage after strenuous exercise. Am J Physiol Cell Physiol. 2001; 280(6):C1570-5

4. Michailidis $Y$, Karagounis LG, Terzis G, Jamurtas AZ, Spengos K, Tsoukas D, Chatzinikolaou A, Mandalidis D, Stefanetti RJ, Papassotiriou I, et al. Thiolbased antioxidant supplementation alters human skeletal muscle signaling and attenuates its inflammatory response and recovery after intense eccentric exercise. Am J Clin Nutr. 2013;98(1):233-45.

5. Byrne C, Eston R. The effect of exercise-induced muscle damage on isometric and dynamic knee extensor strength and vertical jump performance. J Sports Sci. 2002;20(5):417-25.

6. Byrne C, Eston R. Maximal-intensity isometric and dynamic exercise performance after eccentric muscle actions. J Sports Sci. 2002;20(12):951-9.

7. Connolly DA, McHugh MP, Padilla-Zakour OI, Carlson L, Sayers SP. Efficacy of a tart cherry juice blend in preventing the symptoms of muscle damage. $\mathrm{Br}$ J Sports Med. 2006:40(8):679-83. discussion 683

8. Machin DR, Christmas KM, Chou T-H, Hill SC, Van Pelt DW, Trombold JR, Coyle EF. Effects of differing dosages of pomegranate juice supplementation after eccentric exercise. Phys J. 2014;2014:7.

9. McLeay Y, Barnes MJ, Mundel T, Hurst SM, Hurst RD, Stannard SR. Effect of New Zealand blueberry consumption on recovery from eccentric exerciseinduced muscle damage. J Int Soc Sports Nutr. 2012;9(1):19.

10. Connolly DA, Lauzon C, Agnew J, Dunn M, Reed B. The effects of vitamin C supplementation on symptoms of delayed onset muscle soreness. J Sports Med Phys Fitness. 2006;46(3):462-7.

11. Bryer SC, Goldfarb AH. Effect of high dose vitamin C supplementation on muscle soreness, damage, function, and oxidative stress to eccentric exercise. Int J Sport Nutr Exerc Metab. 2006;16(3):270-80. 
12. Teixeira VH, Valente HF, Casal SI, Marques AF, Moreira PA. Antioxidants do not prevent postexercise peroxidation and may delay muscle recovery. Med Sci Sports Exerc. 2009;41(9):1752-60.

13. Bagchi D, Roy S, Patel V, He G, Khanna S, Ojha N, Phillips C, Ghosh S, Bagchi M, Sen CK. Safety and whole-body antioxidant potential of a novel anthocyanin-rich formulation of edible berries. Mol Cell Biochem. 2006; 281(1-2):197-209.

14. Bagchi D, Sen CK, Bagchi M, Atalay M. Anti-angiogenic, antioxidant, and anti-carcinogenic properties of a novel anthocyanin-rich berry extract formula. Biochemistry (Mosc). 2004;69(1):75-80. 71 p preceding 75

15. Merry TL, Ristow M. Do antioxidant supplements interfere with skeletal muscle adaptation to exercise training? J Physiol. 2016;594(18):5135-47.

16. Levers K, Dalton R, Galvan E, Goodenough C, O'Connor A, Simbo S, Barringer N, Mertens-Talcott SU, Rasmussen C, Greenwood M, et al. Effects of powdered Montmorency tart cherry supplementation on an acute bout of intense lower body strength exercise in resistance trained males. J Int Soc Sports Nutr. 2015;12:41.

17. Buckley JD, Thomson RL, Coates AM, Howe PR, DeNichilo MO, Rowney MK. Supplementation with a whey protein hydrolysate enhances recovery of muscle force-generating capacity following eccentric exercise. J Sci Med Sport. 2010:13(1):178-81.

18. Etheridge T, Philp A, Watt PW. A single protein meal increases recovery of muscle function following an acute eccentric exercise bout. Appl Physiol Nutr Metab. 2008;33(3):483-8.

19. Nosaka K, Sacco P, Mawatari K. Effects of amino acid supplementation on muscle soreness and damage. Int J Sport Nutr Exerc Metab. 2006;16(6):620-35.

20. Shimomura Y, Yamamoto Y, Bajotto G, Sato J, Murakami T, Shimomura N, Kobayashi H, Mawatari K. Nutraceutical effects of branched-chain amino acids on skeletal muscle. J Nutr. 2006;136(2):529s-32s.

21. Papacosta E, Nassis GP, Gleeson M. Effects of acute postexercise chocolate milk consumption during intensive judo training on the recovery of salivary hormones, salivary SlgA, mood state, muscle soreness, and judo-related performance. Appl Physiol Nutr Metab. 2015:40(11):1116-22.

22. Ra SG, Miyazaki T, Ishikura K, Nagayama H, Komine S, Nakata Y, Maeda S, Matsuzaki $Y$, Ohmori $\mathrm{H}$. Combined effect of branched-chain amino acids and taurine supplementation on delayed onset muscle soreness and muscle damage in high-intensity eccentric exercise. J Int Soc Sports Nutr. 2013;10(1):51.

23. Farup J, Rahbek SK, Knudsen IS, de Paoli F, Mackey AL, Vissing K. Whey protein supplementation accelerates satellite cell proliferation during recovery from eccentric exercise. Amino Acids. 2014;46(11):2503-16.

24. Rathbone CR, Wenke JC, Warren GL, Armstrong RB. Importance of satellite cells in the strength recovery after eccentric contraction-induced muscle injury. Am J Phys. 2003;285(6):R1490-5.

25. Chatterjee A, Yasmin T, Bagchi D, Stohs SJ. Inhibition of helicobacter pylori in vitro by various berry extracts, with enhanced susceptibility to clarithromycin. Mol Cell Biochem. 2004;265(1-2):19-26.

26. Zafra-Stone S, Yasmin T, Bagchi M, Chatterjee A, Vinson JA, Bagchi D. Berry anthocyanins as novel antioxidants in human health and disease prevention. Mol Nutr Food Res. 2007;51(6):675-83.

27. Miles MP, Pearson SD, Andring JM, Kidd JR, Volpe SL. Effect of carbohydrate intake during recovery from eccentric exercise on interleukin- 6 and muscledamage markers. Int J Sport Nutr Exerc Metab. 2007;17(6):507-20.

28. Green MS, Corona BT, Doyle JA, Ingalls CP. Carbohydrate-protein drinks do not enhance recovery from exercise-induced muscle injury. Int J Sport Nutr Exerc Metab. 2008;18(1):1-18.

29. Li RC, Wu Y, Maffulli N, Chan KM, Chan JL. Eccentric and concentric isokinetic knee flexion and extension: a reliability study using the Cybex 6000 dynamometer. Br J Sports Med. 1996;30(2):156-60.

30. Impellizzeri FM, Bizzini M, Rampinini E, Cereda F, Maffiuletti NA. Reliability of isokinetic strength imbalance ratios measured using the Cybex NORM dynamometer. Clin Physiol Funct Imaging. 2008;28(2):113-9.

31. Bijur PE, Silver W, Gallagher EJ. Reliability of the visual analog scale for measurement of acute pain. Acad Emerg Med. 2001;8(12):1153-7.

32. Judge $L W$, Burke JR. The effect of recovery time on strength performance following a high-intensity bench press workout in males and females. Int J Sports Physiol Perform. 2010;5(2):184-96.

33. Elmer SJ, McDaniel J, Martin JC. Alterations in neuromuscular function and perceptual responses following acute eccentric cycling exercise. Eur J Appl Physiol. 2010;110(6):1225-33.
34. Goldfarb AH, Garten RS, Cho C, Chee PD, Chambers LA. Effects of a fruit/ berry/vegetable supplement on muscle function and oxidative stress. Med Sci Sports Exerc. 2011;43(3):501-8.

35. Kato H, Suzuki H, Mimura M, Inoue Y, Sugita M, Suzuki K, Kobayashi H. Leucine-enriched essential amino acids attenuate muscle soreness and improve muscle protein synthesis after eccentric contractions in rats. Amino Acids. 2015;47(6):1193-201.

36. Trombold JR, Barnes JN, Critchley L, Coyle EF. Ellagitannin consumption improves strength recovery 2-3 d after eccentric exercise. Med Sci Sports Exerc. 2010;42(3):493-8.

\section{Submit your next manuscript to BioMed Central and we will help you at every step:}

- We accept pre-submission inquiries

- Our selector tool helps you to find the most relevant journal

- We provide round the clock customer support

- Convenient online submission

- Thorough peer review

- Inclusion in PubMed and all major indexing services

- Maximum visibility for your research

Submit your manuscript at www.biomedcentral.com/submit
Biomed Central 